\title{
La formación de ciudadanía en México a través de las radios comunitarias. Caso: Radio Teocelo, Veracruz
}

\author{
The formation of citizenship in Mexico through \\ community radios. Case: Radio Teocelo, Veracruz
}

\author{
Mónica Mendoza Madrigal* \\ Universidad de Xalapa \\ Km 2. Carretera Xalapa-Veracruz, núm. 34, Col. Acueducto Ánimas, \\ C.P. 91190, Xalapa, Veracruz, México
}

Editor: Rogelio del Prado Flores mmendozam@hotmail.com

https://orcid.org/0000-0002-8857-3764

\section{RESUMEN}

$\mathrm{E}$ sta investigación plantea cómo las audiencias han modificado su consumo de medios, transformando tal dinámica en un proceso que requiere de ciudadanos participativos, que acceden al espacio público a través de los medios de comunicación para formar parte de la toma de decisiones colectivas para coparticipar del ejercicio del poder. En tal sentido, por medio de este trabajo se plantea que otras formas posibles de comunicar permiten reconstruir el tejido social fracturado en los modelos de comunicación comercial y público, haciendo posible el fortalecimiento de la democracia de manera auténtica, a través de medios cuyos contenidos fortalezcan la identidad, los valores y la cultura de sus regiones, al tiempo que aportan información específica de interés para sus audiencias, atendiendo a un reclamo social en zonas o regiones en donde los públicos no forman parte de la segmentación que interesa a otros modelos de medios. Así es como las radios comunitarias surgen y tienen

* Doctora en Investigación de la Comunicación por la Universidad Anáhuac México; Maestra en Comunicación Política por el Centro Avanzado de la Comunicación; Licenciada en Ciencias de la Comunicación por la Universidad Cristóbal Colón. Complementa su formación con diplomados en Derecho parlamentario, Derechos Humanos e Igualdad de Género por el Congreso del Estado de Veracruz; Comunicación Política por la UNAM; Gobernanza y participación ciudadana por el Instituto Mora; y Género, por El Colegio de México. Tiene 20 años diseñando y aplicando estrategias de comunicación política en campañas políticas y en instituciones públicas. Catedrática en la Universidad Anáhuac de Xalapa y la Universidad de Xalapa. Ponente nacional e internacional en Argentina, Uruguay, Cuba y Ecuador. 
valor para sus comunidades, en un trabajo que debe estar garantizado por el Estado, pues es a él al que le corresponde garantizar su funcionamiento en forma democrática, brindando la pluralidad y el equilibrio necesarios para facilitar el acceso de las audiencias al espacio público a fin de intervenir en la discusión y toma de decisiones de competencia colectiva, mediante el ejercicio efectivo de ciudadanía.

Palabras clave: Estado, comunicación ciudadana, representaciones sociales, radios comunitarias, ciudadanía.

\section{ABSTRACT}

This research raises how audiences have modified their media consumption, transforming such dynamics into a process that requires participatory citizens, who access the public space through the media to be part of collective decision-making to participate in the exercise power. In this sense, through this work it is proposed that other possible ways of communicating allow the reconstruction of the fractured social fabric in commercial and public communication models, making it possible to strengthen democracy in an authentic way, through media whose contents strengthen the identity, values and culture of their regions, while providing specific information of interest to their audiences, attending to a social claim in areas or regions where audiences are not part of the segmentation that interests other media models. This is how community radio stations arise and have value for their communities, in a job that must be guaranteed by the State, since it is this one that is responsible for guaranteeing its functioning in a democratic way, providing the plurality and balance necessary to facilitate the audience access to public space in order to intervene in the discussion and decision making of collective competence, through the effective exercise of citizenship.

Keywords: State, citizen communication, social representations, community radios, citizenship.

\section{INTRODUCCIÓN}

Para arribar al problema de estudio en que se funda esta la investigación, se partió de analizar la realidad actual y las problemáticas sociales, políticas, económicas y culturales que ocurren en el marco de la comunicación, lo que permite observar la existencia de una ruptura entre 
el sujeto y el Estado que deriva en una pérdida de legitimidad y de confianza presente en todos los ámbitos de interacción humana.

Esta situación tiene síntomas específicos, como lo es el hecho de que al no confiar las personas en el Estado para ser éste el conductor de los procesos de vida, entonces deja de reconocer como válidos los principios de autoridad que rigen la vida cotidiana, rompiendo los vínculos que unen a las personas con ese ente al que se alude, pues ya no representa un factor de unión; dejando de sentirse representados por quienes deberían tener el legítimo derecho a la toma de decisiones públicas, y más aún, sintiéndose excluidos de ese proyecto conjunto llamado comunidad.

Todos estos aspectos confluyen en un solo punto: el ser humano no se asume como ciudadano y, por tanto, vive en un mundo del que es ajeno, con el que no interactúa, con el que no se involucra, del que no participa.

El proceso, en efecto, pareciera contradictorio, pues tiene lugar en la época donde los límites territoriales se han diluido en el gran mapamundi de la globalización y donde no hay distancias que nos separen, pues es posible mantener contacto gracias a las tecnologías de la información y la comunicación. Pero ¿acaso es posible que a pesar de estos avances logrados tanto por el desarrollo de la tecnología como por los acuerdos internacionales, los seres humanos no estén ejerciendo una plena ciudadanía?

Los datos asílo indican. Para conocer la calidad de la ciudadanía en México, el Instituto Nacional Electoral y El Colegio de México efectuaron en 2016 un estudio denominado "Informe País", cuyas conclusiones son reveladoras: "México se encuentra inmerso en un complejo proceso de construcción de ciudadanía” (2016, p. 69), mismo que a decir de los indicadores evaluados por el estudio se caracteriza por la desconfianza generalizada que se tiene tanto hacia el otro como hacia la autoridad.

Dado que la ciudadanía es la base de la democracia (Olvera, 2016), el que un estudio como el antes referido revele los bajos índices de la calidad de la ciudadanía pone de manifiesto el desencanto que existe hacia la democracia y da cuenta del porqué ésta no ha terminado de afianzarse en los más de cien años en que en México se ha tratado de alcanzarla.

En tal sentido, vale la pena preguntarse ¿¿de quién es tarea la ciudadanía? Sin duda alguna, la respuesta es: de todos. Los tres actores que participan del Estado - gobierno, empresas y ciudadanos-, cada uno tiene responsabilidades que les competen para hacer que la parte social de su conjunto esté fortalecida, pues en la medida en la que esto ocurra, el gran grupo que entre los tres constituyen se desempeñará en la escena pública en condiciones de mayor equilibrio, favoreciendo su desarrollo.

Entonces, ¿ila ciudadanía se construye o se forma? Esta investigación sostiene que ambos procesos tienen lugar cuando se habla de ciudadanía. Por lo que respecta a la cons- 
trucción, ello corresponde a las instituciones socializadoras del sujeto y a los grupos con los que éste se relaciona en su etapa temprana: la familia y la escuela, que son a quienes les corresponde sentar las primeras enseñanzas sobre lo que implica ser ciudadano y que son implícitas, pues se aprenden mediante el ejemplo, y explícitas, a través de su reiteración doctrinaria.

Sin embargo, estas instituciones y grupos sociales a los que el sujeto pertenece y se incorpora de manera formal, no son las únicas que le proporcionan aprendizajes respecto del mundo social. Están, desde luego, los grupos informales como son: los vecinos, los amigos, los compañeros de trabajo, los otros seres humanos y los medios de comunicación.

Estos últimos son los agentes socializadores por excelencia, con los que el ser humano convive de muy diversas maneras, haciendo imprecisa la cantidad de tiempo que pasa en contacto con ellos, dado el sistema de multiplataformas que existe en la actualidad.

De las distintas funciones que desempeñan, los medios de comunicación ejercen una que para efectos de esta investigación es fundamental: construyen representaciones y lo hacen mediante sus contenidos, trabajo de conductores y locutores y su programación que van dando cuenta de valores, actitudes, comportamientos, aspiraciones y deseos. Todo ello gracias a una serie de símbolos conscientes e inconscientes que construyen y de-construyen significados que son atribuidos al mundo de vida.

Es por el cumplimiento de esta función que se atribuye a los medios de comunicación la posibilidad de formar ciudadanía, tema en el que se centra esta investigación. Sin embargo, no todos los medios tienen esta posibilidad.

De entre todas las formas posibles de comunicar, son los medios comunitarios y en específico, la radio, la que puede formar ciudadanía entre sus audiencias, ya que establecen con ellas una relación directa, cercana, de amplio conocimiento de sus intereses y necesidades informativas, pero también, con la apertura necesaria para que sean directamente ellas las que accedan a los micrófonos para apropiarse del medio y hacer comunidad a través de su voz.

Para comprobar si los medios comunitarios son formadores de ciudadanía, se eligió a un medio comunitario en concreto: Radio Teocelo, también llamada la abuela de las radios comunitarias. Tiene más de 50 años de vida en el cuadrante y fue la primera en el país en contar con un permiso oficial para sus transmisiones, y que habiendo surgido en forma casi experimental, ha sido radio cultural, radio popular y hoy radio comunitaria, logrando sobrevivir a procesos internos y externos que refrendan su compromiso con la comunidad a la que sirven y ante la que hoy enfrentan quizá el mayor de sus retos: migrar de frecuencia y transitar hacia la digitalización de su señal. 


\section{ESTADO DEL ARTE}

Luego de problematizar el tema elegido, es necesario fundamentarlo teóricamente, para lo cual uno de los logros más significativos de esta investigación ha sido encontrar la propuesta teórica que más se adecúa al tema.

Las llamadas corrientes teóricas clásicas de la comunicación han explicado desde inicios del siglo pasado los procesos que tienen lugar en los denominados medios tradicionales, a saber: prensa, radio, cine y televisión, tratando de comprender la compleja relación guardada entre estos, siendo la forma más conocida de desarrollarse la que corresponde al modelo comercial; sin embargo, ni esa forma de uso atribuido a los medios es la única existente —están también los medios públicos y los medios comunitarios - ni los medios en cuestión persisten en su forma originaria, pues han convergido hacia otros modelos vigentes en la actualidad, como es el caso de los medios digitales.

Es así como ha habido un proceso de cambio en los enfoques teóricos mediante los cuales se estudian los fenómenos mediáticos.

Es la académica de origen colombiano integrante del cuerpo de investigadores de la Universidad de Ohio, Clemencia Rodríguez, quién propone en 2001 el término de "comunicación ciudadana” en su libro Fissures in the Mediascape, planteándolo como heredero de una larga tradición de estudios surgidos en América Latina desde varias décadas atrás, tiempo en el cual se han asignado a este tipo de comunicación nombres como: alternativa, radical, ciudadana, marginal, participativa, de contra-información, paralela, comunitaria, underground, popular, libre, disidente, de resistencia, pirata, clandestina, autónoma y otros, todos ellos atribuidos a un proceso comunicativo, cultural y mediático totalmente distinto del que corresponde a la comunicación masiva.

Teniendo como antecedente de este abordaje primero a la llamada "Comunicación Participativa para el Desarrollo", cuyo trabajo se sitúa a finales de los años cuarenta del siglo pasado y se centra en la participación ciudadana dirigida al cambio social gestionado desde los propios medios; seguida por la Comunicación Alternativa que ejerció un tipo de monopolio sobre el ámbito de lo local que fue desplazado desde mediados de la década de los ochenta también de la pasada centuria, por un nuevo enfoque denominado "Comunicación Participativa" que se asocia con la democracia y que reubica el poder e influye en el proceso de toma de decisiones de los grupos sociales de acuerdo con sus propias capacidades autogestivas y sus dinámicas culturales, y que fue replanteado a través de la Comunicación para el Cambio Social, paradigma que se basa no en el uso de un tipo de medios en particular, sino en el diseño de una estrategia tendiente a generar procesos sociales de cambio a partir de la propia experiencia de las comunidades. 
Con esta tradición en abordaje de una forma de hacer comunicación y ante la llegada del nuevo siglo, se convoca a recuperar los aprendizajes que aportaron cada uno de los modelos de comunicación desarrollados a lo largo de más de seis décadas y de los cuales deriva la apuesta teórica planteada por Clemencia Rodríguez, misma que propone denominar comunicación ciudadana a "los procesos mediáticos a partir de su potencial para desencadenar procesos de cambio social” (2009, p. 17), alejándolo de cualquier comparación directa respecto de los medios masivos y concentrándose en el proceso cultural y social que se desencadena cuando las comunidades se apropian de ciertos recursos comunicativos, lo que significa una clara distinción de conceptos como comunicación comunitaria porque en su perspectiva esa forma de denominación alude solo a quienes producen la comunicación, o bien, de comunicación alternativa, misma de la que opina se define a partir de lo que no es, aceptando un estatus menor al que poseen los medios considerados dominantes, por lo que en lo sucesivo será claro que la comunicación que realizan los medios comunitarios no puede ser llamada comunicación alternativa.

Por tanto, "los medios ciudadanos son aquellos que facilitan la transformación de individuos y comunidades... abriendo espacios de comunicación... y adquiriendo poder para nombrar el mudo en sus propios términos... activando un proceso a través del cual los individuos y las comunidades re-codifican tanto sus contextos como su propia identidad" (Rodríguez, 2009, p. 19), lo cual facilita que se constituyan los medios que utilizan los ciudadanos para activar los procesos de comunicación que son propios en sus comunidades.

De acuerdo con el término propuesto por Rodríguez (2009), no todos los medios comunitarios son ciudadanos pues ello depende del proceso que lleva a cabo el medio para construir su comunicación, pero en el caso del trabajo específico que realiza Radio Teocelo, la definición encuentra plena correspondencia con la labor que ahí se lleva a cabo.

En tal sentido, es indispensable construir nuevos marcos teóricos en los cuales sea posible dar fundamento y solidez a esta propuesta, buscando con ello un discurso más amplio para comprender los procesos comunicativos que ocurren al interior de las comunidades y que influyen en la recepción de los mensajes, pues en esta óptica los medios se convierten en narradores dentro de un marco de completa pluralidad, haciendo de la comunicación un ejercicio de permanente interacción que influye en las relaciones sociales de las comunidades, lo que sucede debido a que el sujeto es re-significado a través de ese proceso del que forma parte, permitiendo entender a los medios ciudadanos "como aquellos facilitadores de procesos donde los individuos o sujetos pasivos se transforman en ciudadanos o sujetos activos de lo político y lo público" (Navarro, 2010, p. 36), lo que de facto ocurre con la forma de entender al sujeto social receptor-audiencia-ciudadano que se aborda en esta investigación. 
Es importante reconocer que dado que la comunicación ciudadana no está definida por ningún tipo de medio en particular, su receptor se re-define y se transforma en ciudadano, mismo que es entendido como "la persona que cada día genera poder en medio de sus relaciones cotidianas y usa este poder para ir transformando su comunidad poco a poco" (Navarro, 2010, p. 39).

\section{MARCO TEÓRICO. NUEVA CONCEPTUALIZACIÓN}

Los medios ciudadanos facilitan la apropiación simbólica, ya que re-decodifican el entorno desde el uso de sus propios códigos y también al sujeto social a través de la reafirmación de las identidades ligadas a lo local, convirtiéndose en relator de su propia historia para lo cual se exploran todas las posibilidades comunicativas disponibles.

Esta función es sustantiva, ya que se reconoce a la ciudadanía como una construcción social lograda a partir de referentes obtenidos del contexto, lo que da lugar a recurrir a la teoría de las representaciones sociales a partir de los planteamientos realizados por Serge Moscovici, siendo los medios de comunicación actores indispensables de dicho proceso.

En tal sentido es necesario realizar dos precisiones. La primera es que esta investigación se centra en la formación de ciudadanía y no en el funcionamiento de los medios y la segunda es que se identifica a las radios comunitarias como medios de comunicación colectiva y no como medios masivos, aspecto que es central en la teoría de las representaciones sociales pues la visión de lo colectivo tiene un peso central dada la interacción de un sujeto con otro, lo que claramente ocurre al estudiar a la audiencia de las radios comunitarias desde su condición de ciudadanos y no solo en su papel de receptores del mensaje de un medio, permitiendo que a partir de los contenidos emitidos se desarrolle una identidad personal y social, y tenga lugar la búsqueda de sentido y de construcción del conocimiento que define a la comunidad.

De tal manera que resulta indispensable identificar los valores, creencias y actitudes "en que la ciudadanía es vivida por los ciudadanos” (Gutiérrez Vidrio, 2011, p. 2), entendiendo que se trata de una construcción social que surge de las relaciones e interacciones del individuo con los ámbitos de convivencia, buscando con ello construir una representación más amplia: la de la democracia, que es el ideal hacia el cual se conduce la existencia de una ciudadanía participativa e informada.

Para analizar el objeto de estudio en que se funda la investigación realizada, se tomó como eje la relación Estado-medios de comunicación-ciudadanía que da lugar al sistema de medios existente y que constituye la base de las formas democráticas existentes. 
El estudio de la relación de estos tres actores pone de manifiesto el agotamiento del modelo tradicional de Estado-nación que propicia la erosión de la política como forma de organizar la vida de las sociedades, deviniendo en una inequitativa distribución del poder que impide a la ciudadanía acceder al espacio público, lugar simbólico en donde se dirimen los asuntos de competencia colectiva, lo cual ha traído como resultante una creciente apatía, falta de cohesión social, identidad y participación ciudadana.

Ante ello, surgen alternativas de inclusión que plantean algunos caminos para hacer frente al problema que da origen a la investigación.

El primer camino surgido es la gobernanza, que se constituye como una posibilidad para reestablecer los equilibrios sociopolíticos, ya que incorpora al proceso de toma de decisiones a otros actores, sumándolos activamente al Estado para entonces sí dirimir los asuntos de competencia colectiva.

Este enfoque involucra necesariamente a los medios de comunicación en una variante específica denominada gobernanza comunicacional, en la cual se incluye a todas las voces en la suma de los participantes del proceso de discutir los asuntos públicos, abarcando no solo a los medios como industria — lo que ha sido una práctica común—, sino a la totalidad de sus formas de organización, es decir, además de los medios comerciales, también se incluye a los medios públicos y a los medios social-comunitarios.

Tal inclusión de formas y de voces tiene sentido, gracias al segundo camino propuesto para complementar el enfoque que engloba a esta investigación: el derecho humano a comunicar, gracias al cual los medios de comunicación se asumen como garantes auténticos de la libertad de expresión en un sentido de ida y vuelta, lo que involucra a audiencias que ahora sí son tomadas en cuenta y respetadas desde una óptica basada en los derechos humanos y no en el consumismo.

Si bien el derecho a comunicar no ha logrado traducirse en un marco legal válido, lo cierto es que sin esa perspectiva, modificaciones legales como las reformas que dan lugar a la Ley Federal de Telecomunicaciones y Radiodifusión aprobada en 2013 seguirán estando limitadas de abarcar por completo la magnitud del fenómeno que abordan, porque legislarán sobre asuntos específicos — los más urgentes — siendo permanentemente rebasadas por un fenómeno que avanza a pasos agigantados.

Este planteamiento viene de la mano del tercer camino que se abre a partir de este enfoque: el reconocimiento al papel que desempeñan las audiencias como productoras y receptoras del mensaje que los medios de comunicación les dirigen, asumiendo como válida la afirmación de que las denominadas audiencias activas serán entonces ciudadanías participativas, identidad fundamental para alcanzar el objetivo de investigación trazado. 
Con este enfoque se subraya la premisa de que es con la participación ciudadana que se logrará transitar hacia la democracia, aludiendo no solo a la democracia política sino sobre todo a la democratización de los medios, por lo que al acudir a conceptos como gobernanza, derecho a la comunicación y audiencias se consolida un enfoque participativo, inclusivo y de respeto a los derechos humanos, congruentes con el fin de lograr una "distribución más justa de la palabra” (Bruzzone, 2015, p. 13), tarea que involucra el reconocimiento de otros medios de comunicación, otros públicos y, desde luego, otros contenidos, en un proceso de profundo cambio que no solo ocurre a nivel de acceso de los medios o de su uso y consumo, sino que implica una re-construcción de sí mismos.

\section{ENCUADRE TEMÁTICO}

El análisis sistémico de la relación Estado-medios de comunicación-ciudadanía, así como la reflexión en torno a procesos intervinientes y resultantes de cada uno de ellos como son el espacio público, la democracia, el exceso de concentración mediática y la falta de pluralismo en medios, forman parte del andamiaje en que se funda una nueva manera de relacionarse socialmente, entendiendo que no hay democracia sin Estado, no hay Estado sin medios de comunicación y no hay ni Estado ni medios de comunicación sin una ciudadanía fortalecida.

Para este proceso de elevar los asuntos privados al ámbito público es necesario fortalecer la relación que existe entre comunicación y ciudadanía fundada en "la construcción de lo público, la constitución de los medios y las imágenes en un espacio de reconocimiento social y el de las nuevas formas de existencia y ejercicio de la ciudadanía" (Barbero, 2011, p. 46), obedeciendo a una nueva narrativa en la que es posible observar un retorno de lo público para lo que es necesario construir una "nueva mediación de la política" (Barbero, 2011, p. 39) donde claramente hay también una nueva ciudadanía que inaugura sus propios modos de representación y de participación.

Es así como la condición ciudadana está dada a partir de su participación en el espacio público, lo que le faculta con el "poder de acceder como emisor, a la comunicación pública" (Barbero, 2011, p. 5), transformando la tradicional relación Estado-medios-ciudadanía para dar lugar a nuevas formas de ser, estar y pensar.

Este proceso, por sencillo que parezca, se dificulta debido a que el sistema de medios se ha regido por procesos nada democráticos, que han impedido una participación plural de sus audiencias.

Y es que los medios de comunicación han sido acompañantes del ser humano en cada una de sus distintas etapas de vida y han evolucionado paulatinamente en función del con- 
texto que los cobija. Así es como de los medios primitivos se transitó a formas de expresión propias del medievo y de la época colonial, hasta llegar a los de la era industrial, derivando en los electrónicos, que dieron voz e imagen en movimiento a la realidad.

A partir de ese momento, la comunicación mediática se destinó a las masas, constituyéndose en un fenómeno con severas implicaciones para todos los ámbitos del quehacer social.

Tan solo en México, en el momento de definir el modelo de comunicación a implementar se consideró la existencia de medios comerciales y públicos, confiriéndole el Estado al primero de ellos todas las facilidades necesarias para que las incipientes empresas de este giro florecieran, mientras que desde sus etapas tempranas los medios públicos fueron mal encaminados y mal dirigidos, confinándolos a la obsolescencia o a la competencia limitada de contenidos y programación para las audiencias.

Esta situación sentó las bases de lo que en breve ocurrió: el exceso de concentración mediática en manos privadas, que impusieron un criterio comercial en la creación de una industria cultural que, durante décadas, no tuvo competencia y que cuando la tuvo, no representó la posibilidad de mejorar el nivel de los contenidos para ofertarlos a una audiencia con capacidad de elegir entre dos opciones distintas, sino que tendieron a dividirse el mercado con productos estandarizados que en poco o nada representaron variedad en términos de formatos y contenidos.

El fenómeno de la concentración mediática ha engendrado distintos vicios que no solo atañen a quienes se encuentran involucrados en la industria de medios, pues al ser los responsables de la falta de pluralismo mediático, han inhibido la libertad de expresión y el derecho de información de todas sus audiencias y a partir de los efectos sociales que los medios de comunicación generan, han impactado a toda la población.

Y como en todos los totalitarismos, la ruptura ha procedido del punto más sensible: las audiencias, que han retirado su credibilidad hacia los contenidos ofertados por los medios comerciales y han virado en su preferencia hacia la oferta que le brindan otras opciones mediáticas que hoy se presentan con suficiente variedad.

No se trata únicamente de las múltiples opciones que brinda el acceso a dispositivos con internet, sino que en el menú de ofertas mediáticas disponibles, en realidad lo que hoy se potencia es la convivencia con formas de comunicación que tienen décadas de existir y que siguen vigentes, como lo es el caso de los medios públicos y los medios social-comunitarios.

Estos últimos vienen de recorrer un largo camino, con décadas de lucha por parte de las comunidades en donde se originan para tener un medio de comunicación propio, que se ocupe de difundir los temas que lesinteresan de manera concreta. Y es que esas comunidades de la sierra o del campo, que incluso hablan en su lengua natal, lo que quieren saber es cómo poder arar mejor sus tierras o cómo protegerse en caso de que el volcán haga erupción. 
Para ellos, la forma más económica para mantenerse comunicados fue improvisando transmisores de radio, con antenas hechizas y con potencias limitadas en alcance, pero suficientes en voluntad y en contenidos para hacer lo que esos grandes consorcios mediáticos olvidaron: comunicar.

La historia de los medios comunitarios proviene de mediados del siglo pasado en América Latina y surge a partir de proyectos auspiciados por grupos religiosos, que logran hacer germinar su semilla porque se asocian con las causas sociales de grupos y comunidades en donde la suya era el arma que hacía falta. La voz del cuadrante es un soldado más en la batalla que las comunidades emprendían para hacerse escuchar.

Es, por tanto, fácil comprender por qué el suyo ha sido un camino tan plagado de tempestades. Primero, por la falta de recursos económicos de las comunidades para hacer funcionar a sus medios, y luego, porque en la medida en que por medio de estas radios se cuestionaba al poder y a los poderosos, ellos mismos se encargaban de obstaculizarlas.

A nivel nacional estos medios fueron condenados a la ilegalidad durante décadas, haciendo de la búsqueda para la obtención de un permiso de transmisión su principal proclama. En ese camino, su voz tuvo eco más allá de sus propias comunidades, porque se hizo bandera de colectivos y organizaciones de la sociedad civil y de la academia, tanto en el país como fuera de éste, vinculando su lucha con un derecho que ahora es reconocido: el derecho humano a comunicar.

No se trata solamente de reconocer que a todos los asiste el derecho de ser informados o que todos tienen derecho a la libre expresión de las ideas, sino de ir más allá. En donde como ciudadanos es posible exigir contenidos mediáticos que respeten los derechos. Que no utilicen a sus audiencias como meros consumidores de productos que vender, sino como seres conscientes, que exigen veracidad en la información que se recibe.

Este argumento, que ha sido abrazado desde otros países de América Latina y por organismos internacionales como la Organización de las Naciones Unidas y la Comisión Interamericana de los Derechos Humanos, es la aspiración para la armonización legislativa en este país, pues no existe aún como tal.

En los últimos años ha habido un notable avance legislativo que ha permitido que las radios comunitarias pasen de la ilegalidad a un marco legal que las reconoce y las protege. La reforma constitucional de 2012, que derivó en Ley Federal de Telecomunicaciones y Radiodifusión hoy vigente, otorga certidumbre jurídica a estos medios a través de la figura de concesiones para radios de uso social-comunitarias, lo cual de entrada significa un avance importante en la lucha de estos medios de comunicación que siguen enfrentando serias limitaciones para acceder a recursos económicos, lo que tiene fuertes repercusiones técnicas que afectan la calidad de sus transmisiones. De tal manera que la batalla de las radios comunitarias no tiene reposo. 
En esta época de esplendor de los medios digitales, la lucha de los comunitarios podría parecer fuera de lugar, pero de acuerdo con la investigación realizada, lo que se reivindica es el derecho de todos los ciudadanos a acceder a cuantos medios de comunicación tenga a su alcance sin menoscabo del tipo de medios de que se trate. Así lo dice Clemencia Rodríguez (2014) señalando que lo que importa es el uso que se dé a los medios y no el tipo de medios que sea.

Si las radios comunitarias son los medios que dan voz a los sin voz, otorgan visibilidad a comunidades que no se encuentran representadas entre las audiencias de otro tipo de medios - llámese comerciales, públicos o digitales- y permiten reestablecer el tejido social al interior, entonces ellas pueden ser formadores potenciales de ciudadanía.

Esta posibilidad la brinda Radio Teocelo, radiodifusora que de acuerdo con la clasificación contenida en la ley vigente en materia de Telecomunicaciones y Radiodifusión se considera como de uso social-comunitario y es la más antigua emisora en su tipo en contar con permiso oficial para sus transmisiones, lo que la convierte en una estación pionera en el país en esta forma de comunicación.

Ubicada en el municipio de Teocelo en el estado de Veracruz a 28 kilómetros de la ciudad de Xalapa, tiene 52 años de vida, habiendo iniciado transmisiones el 1 de septiembre de 1965 con la frecuencia de XEYT Radio Cultural Campesina de Teocelo en el 1490 kilohertz (Khz) de amplitud modulada (AM), con una potencia inicial de 250 watts (Ramos, 2007).

Esta particular forma de hacer comunicación contribuye al rescate de la memoria colectiva de la comunidad y desempeña un papel fundamental, ya que recoge las narrativas de su quehacer cotidiano, permitiendo además que con sus transmisiones se haga conciencia social, fomentando relaciones de cooperación, de solidaridad y de reciprocidad, constituyéndose en un vehículo de gran utilidad para la comunidad pues "ayuda a comprender la intersubjetividad" (Rizo, 2009, p. 68).

Radio Teocelo y su trabajo constante demuestran claramente que los medios en sí mismos no comunican, sino construyen una relación estrecha no tan solo con su audiencia, sino con la comunidad a la que pertenecen ya que quienes bacen la comunicación son las personas, pues como se construyó a lo largo de toda la investigación, "trabajar desde la lógica de la comunicación comunitaria implica trabajar desde la lógica de la inclusión social” (Rizo, 2009, p. 70).

Esa es la labor que este pequeño gran medio realiza en su comunidad y por eso es imprescindible respaldar su existencia y su funcionamiento. 


\section{METODOLOGÍA}

Al constituir Radio Teocelo el estudio de caso en que se aplicó la investigación, se utilizó para ello una técnica mixta combinando lo cuantitativo y lo cualitativo, mediante un estudio de tipo exploratorio, descriptivo y co-relacional.

Por lo que respecta a lo cuantitativo, se utilizó una encuesta aplicada a una muestra de 500 integrantes de la audiencia del medio mayores de edad, entre quienes se buscó conocer si identifican que en el contenido, la programación y el trabajo de los conductores del medio se promueve la formación de ciudadanía.

En la investigación cualitativa se emplearon diversas herramientas entre las que se encuentra, principalmente, la entrevista a profundidad para conocer si en Radio Teocelo existe la intencionalidad explícita de contribuir a la formación de ciudadanía, complementando la información obtenida con lo revelado mediante la aplicación de redes semánticas naturales, que es un instrumento de aproximación al objeto de estudio utilizado para conocer lo que los habitantes de Teocelo piensan respecto a lo que significa ser ciudadano, y se recurrió además a la observación participante a través de la cual se realizó un registro visual de las representaciones de ciudadanía presentes entre la población de la comunidad. En ambos casos — cualitativa y cuantitativa— se buscó operacionalizar los constructos y variables aportadas en la revisión documental y teórica realizada en la primera parte de la investigación.

\section{RESULTADOS}

Por lo que respecta a la investigación cuantitativa, la encuesta reveló que el principal rango de edad entre quienes conforman la audiencia del medio está entre los 25 a 39 años, los cuales constituyen $32 \%$ de la audiencia, segmento que no corresponde con el dato arrojado en el análisis de la programación efectuado en la fase documental en donde fue posible identificar que $88 \%$ de la oferta programática está dirigida a adultos.

La encuesta también mostró que la audiencia está constituida por $53.8 \%$ de mujeres y que el $66 \%$ radica en la cabecera municipal de Teocelo.

Respecto a la información relativa al consumo de medios de la audiencia, el estudio señala que entre quienes gustan leer periódicos $48 \%$ prefiere al Diario de Xalapa, mientras quienes gustan ver televisión la mayoría prefieren a Televisa y TV Azteca (39.2\% al primero y $33.6 \%$ al segundo canal), siendo los noticieros sus programas favoritos.

Fue interesante notar que la mayoría de los encuestados dijeron no tener internet, pero entre quienes sí tienen, señalaron que lo usan para consultar Facebook por encima de páginas de noticias. 
Como se observa, el consumo de medios que se efectúa en la comunidad está muy permeado por la influencia de los medios masivos no locales, por lo que la respuesta a la pregunta de cuál estación de radio prefieren, $61.8 \%$ indicaron que Radio Teocelo resulta de relevancia, pues da cuenta de la acogida que el medio tiene entre la población, señalando además que $23.2 \%$ dicen que su programa favorito es "Rancheritas".

En este mismo tenor se encuentra la respuesta a la pregunta: ¿Por qué escucha Radio Teocelo?, a lo que $44.2 \%$ respondió que por la música. Esa respuesta coincide con el análisis realizado a la programación del medio el cual reveló que $57 \%$ es musical, ello no necesariamente es positivo para un medio que se cataloga a sí mismo como comunitario, lo que implicaría que a través de la programación y contenidos se reafirme el sentido local, lo que al menos en la barra no está presente, añadiendo el dato de que ni siquiera en la programación musical se privilegia la producción de artistas locales.

Precisamente en torno al sentido local de Radio Teocelo fue indispensable consultar a la audiencia respecto de las formas en que interactúa con el medio, considerando que su condición comunitaria estriba precisamente en la posibilidad de que exista una relación de doble vía con retroalimentación directa, por lo que el medio tiene ya establecidas algunas formas de participación como son los talleres de locutores, las rifas y los sorteos, además de la presencia en sus programas, revelando la encuesta que $50.6 \%$ dicen haber participado en las rifas y $46.8 \%$ en los sorteos del medio, dato importante porque muestra que la audiencia hace suyo al medio a través de su participación personal y económica.

En el mismo sentido se indagó sobre si la audiencia ha contactado en forma directa a los conductores, respondiendo 55\% que no lo ha hecho, mientras que quienes sí, la razón ha sido para solicitar alguna complacencia musical.

En ese aspecto hay un gran trabajo por mejorar de parte de la radio, pues aun cuando cuentan con la preferencia y la confianza de la audiencia, no están aportando contenidos que fortalezcan el comunitarismo ni la ciudadanía de entre quienes la escuchan.

Es importante señalar que si bien Radio Teocelo cuenta con un programa pionero en su estilo y reconocido a nivel nacional por fomentar la participación activa en los temas de interés colectivo de la comunidad como es "Cabildo Abierto", este se transmite en forma semanal en cada municipio a donde llega la señal del medio y tiene una hora de duración, por lo que a pesar de que es el programa más importante de la estación, ocupa una posición disminuida dentro de la barra programática, por lo que resulta muy necesario hacer una revisión de la oferta que se brinda a la audiencia para tener un mejor equilibrio entre los contenidos brindados, considerando los perfiles de la audiencia meta que sí están escuchando al medio. 
Y es que además de la larga tradición que como radio comunitaria tiene Radio Teocelo, conserva un gran potencial, como quedó de manifiesto con las respuestas que arrojó el instrumento aplicado, revelando que $51 \%$ de la audiencia confía mucho en el medio.

Adicional a ello y pese a que la investigación no tuvo la intensión de comparar entre Radio Teocelo y las radiodifusoras comerciales y la radio estatal cuyas señales son recibidas en el municipio, es interesante conocer la respuesta dada a la pregunta de si como audiencia se sienten tomados en cuenta por el medio, a lo que $87.2 \%$ dijo que sí, dato que es importante ya que entre las audiencias de los medios comerciales tradicionales no existe este alto nivel de involucramiento entre los radioescuchas con sus medios.

Ello se ve reforzado cuando $61 \%$ de la audiencia señaló que Radio Teocelo sí contribuye a la formación de ciudadanía, indicando $31.9 \%$ de ellos que lo hace porque fortalece la identidad de la comunidad, identificando además en el contenido, la programación y el trabajo de los locutores del medio la presencia de valores que son considerados por la Unesco (2015) como constitutivos de la ciudadanía, como son la sostenibilidad ambiental, igualdad, diversidad, justicia social y defensa de los derechos humanos.

Ahí estriba la riqueza de esta radio, en que tiene una audiencia cautiva que considera al medio como suyo y que le confiere valor y confianza, lo que fortalece su existencia en el cuadrante y da sentido a su presencia como medio.

Como parte del análisis de los resultados aportados por la encuesta se realizaron una serie de pruebas que en primer lugar describieron las variables, lo que se corresponde con los hallazgos antes señalados; posteriormente, se analizaron sus correlaciones, determinando que los aspectos que son estadísticamente significativos para la audiencia son: que el valor de Radio Teocelo más apreciado por su audiencia es el de la sostenibilidad ambiental, reconociendo que el ser tomados en cuenta es un factor que influye para que la audiencia sí considere que la radio contribuye a la formación de la ciudadanía; que la participación de la audiencia con el medio guarda relación con la pertinencia de la programación, lo que indica que a medida que mejore la programación habrá una mayor participación. Esta situación es semejante a la que ocurre cuando la evaluación de la confianza al medio es positiva, lo que incrementa las posibilidades de participar en los programas; así como también sucede cuando el conocimiento que la audiencia tiene de los programas es mayor, lo que hace posible que incremente la participación en los mismos; haciendo indispensable que la programación tenga diversidad, pertinencia y contenidos relevantes y oportunos para incrementar la participación directa de la audiencia.

Debido a que el análisis de los modelos anteriores mostró $64 \%$ de contribución a la predicción de la hipótesis, se hizo necesario someter los resultados a una segunda prueba en la cual se recodificaron las variables, siendo las nuevas: involucramiento percibido con la 
comunidad, actitud hacia los contenidos y percepción sobre los contenidos formativos de ciudadanía y expectativas sobre los medios.

El resultado final de las variables recodificadas permite afirmar que entre mejor sea la actitud de la audiencia hacia los contenidos de Radio Teocelo, mejor será la evaluación que contribuye a la formación ciudadana; y entre mejor sea el grado de involucramiento entre Radio Teocelo y la ciudadanía, mejor será la evaluación de que contribuye a la formación ciudadana.

\section{ANÁLISIS Y DISCUSIÓN}

Del total de las variables de la investigación, en el diseño metodológico efectuado previamente se determinó cuáles de ellas serían abordadas con la encuesta y cuáles serían atendidas a través de las distintas herramientas de la investigación cualitativa, siendo la principal la entrevista a profundidad que fue aplicada excepcionalmente solo a un sujeto, debido a que resultó un informante estratégico dado que se incorporó a Radio Teocelo en la segunda de las cuatro etapas de vida que el medio ha tenido en estos más de 50 años de existencia y pertenece a él desde entonces, además de que está al frente de la asociación civil que opera a la radio (AVERCOP) y ha dirigido a la estación durante los últimos años, siendo uno de los 10 integrantes fijos con que el medio cuenta.

Así es como la información aportada por Elfego Riveros resultó sustantiva para saber que no conocen con claridad el perfil de su audiencia, ni han construido su programación acorde con ello; mantienen una limitada red de convenios con instituciones, siendo que los existentes son para la producción de programas a los que les otorgan espacio a cambio de su producción respectiva en la que el medio no interviene; concentran el trabajo de formación de ciudadanía en el esfuerzo realizado a través del programa "Cabildo Abierto" y a lo que denominan "empoderar a la ciudadanía" para la "intervención municipal”; aunque reconocen que el trabajo de empoderamiento ciudadano tiene limitaciones, como el anonimato y la queja, por lo que quieren seguir formando a su audiencia para salir de ello y ser más propositivos.

En tal sentido, reconocen que su trabajo incide en la participación social comunitaria, tanto como colectivo como medio de comunicación; e identifican la influencia del medio en cuanto a la participación política a través del trabajo que realizan para acercar a las autoridades municipales a la audiencia.

Por lo que respecta a la reglamentación oficial y a la intervención por parte del Estado para atender la realidad específica que como radio comunitaria enfrentan, señala que todavía 
existen inconsistencias respecto al otorgamiento de frecuencias, reconociendo las limitaciones del sector social para ocupar el espectro asignado. Identifican desconocimiento de parte del órgano regulador sobre el trabajo específico que realizan este tipo de medios y consideran que el Estado sigue limitándoles para favorecer a los medios comerciales, señalando que $1 \%$ del otorgamiento de la publicidad oficial para financiar este tipo de medios es más una medida burocrática que un beneficio o aportación a la operación de las comunitarias, reconociendo la imposibilidad financiera que como medio tienen para obtener el recurso que les permita digitalizar al medio y dejando entrever la esperanza por obtener apoyo para no desaparecer.

Señaló que hay una ausencia de políticas públicas para brindar un auténtico equilibrio comunicacional, destacando que la misión de los medios comunitarios es empoderar al ciudadano, para lo cual identifican la función que las representaciones sociales desempeñan tanto en la formación de ciudadanía, como en el proceso de fortalecimiento y apropiación del medio entre la comunidad.

Finalmente, resultó relevante que refiriera que para ellos la inclusión del defensor de las audiencias es una esperanza frente al desánimo existente, pues su audiencia es su fortaleza.

De manera complementaria se aplicó el instrumento llamado Redes Semánticas Naturales que aportó hallazgos sustantivos para conocer de manera específica el significado que la población de Teocelo le atribuye a ser ciudadano, encontrando sesenta y tres distintas respuestas (el instrumento permite que una misma persona aporte más de un significado a cada reactivo), lo cual revela que en términos generales no existe claridad en lo que representa ser ciudadano.

Este instrumento también permitió conocer que la población sí manifiesta participar en actividades de tipo comunitario, pero esa participación está asociada principalmente con una actividad de corte religioso popular.

Estas respuestas directas obtenidas de parte de la población abierta del municipio fueron combinadas con el registro de la Observación Participante, misma que se efectuó en el parque municipal a una hora y un día exprofeso elegido, permitiendo identificar comportamientos que corresponden con la representación social de ciudadanía, como es la solidaridad entre vecinos de la comunidad, el compromiso con la misma a través de las responsabilidades cívicas, el interés por el otro y la identidad con la comunidad, así como la tolerancia e intolerancia social.

La resultante de este ejercicio de observación permitió concluir que en el contexto de la comunidad están presentes algunos comportamientos que contribuyen a construir la representación social de ciudadanía. 


\section{CONCLUSIONES}

La investigación realizada puso de manifiesto una serie de aprendizajes que sucedieron a cada pregunta formulada desde el inicio y que se constituyeron como lámparas que iluminaron el camino del investigador. Desde desnudar el complejo entramado de la relación Estado-medios-ciudadanía en la que se inserta la problemática analizada, hasta comprender que la comunicación es una disciplina tan viva, que brinda enfoques teóricos propios y se apoya de otros aportados por distintas disciplinas para ayudar a entender mucho más que solo fenómenos comunicativos, sino procesos sociales que están en constante transformación.

En ese sentido, el mayor aprendizaje surge de los hallazgos logrados a partir de la aplicación de los instrumentos cuantitativos y cualitativos para el desmenuzamiento del objeto de estudio, comprendiendo que es solo a partir del conocimiento profundo y cercano de una problemática, que es posible aportar propuestas que coadyuven a su atención.

A partir de ello se arriba a conclusiones significativas, siendo la primera de ellas la aportada por el diseño de la investigación que implicó ir más allá de las formas personales de abordaje de la realidad social mediante la aproximación al nodo de estudio con rigor científico, para fundamentar cada uno de los hallazgos y sustentar y revisar las premisas planteadas. Esta forma de construir el conocimiento ha sido reveladora por completo, pues requirió la despersonalización de los saberes y el redescubrimiento de nuevos horizontes de pensamiento.

Una segunda conclusión ocurre en el ámbito disciplinar y yace en el universo develado a partir de las potencialidades que la comunicación ciudadana brinda, pues en ella se trasciende al medio de comunicación utilizado para realizar la práctica comunicativa y se concentra la atención en la finalidad a alcanzar. Por tanto, la comunicación ciudadana es mucho más que un paradigma teórico. Ha sido un descubrimiento en el sentido de que existen otras formas posibles de hacerlo, lo que en la era de las comunicaciones digitales resulta fundamental, ya que hace evidente que ni todas las personas tienen una manera única de ponerse en contacto con el otro, ni los medios de comunicación son instrumentos infalibles; por lo cual la preminencia no radica en el objeto con el que se comunica, sino en el fin al que esa comunicación sirve, devolviendo a la comunicación su sentido original de poner en común unión, saberes y circunstancias a partir de las cuales es posible hacer comunidad.

Esta óptica reivindica a la comunicación misma, pues le brinda la facultad de reconocer al otro reconociéndose uno mismo, de reaprender del otro aprendiendo de sí mismo, y de comunicar al otro comunicándose a sí mismo.

La comunicación ciudadana es la posibilidad de humanizar las comunicaciones. 
Con la comunicación ciudadana es posible hacer comunidad y es posible ser ciudadanos. Empodera a la audiencia contribuyendo a una comunicación mediática legitimada, pues no sólo recibe los contenidos, sino que coparticipa de ellos, fortaleciendo el derecho a la comunicación como un derecho de "doble vía”. Gracias a ello es posible garantizar plenamente la libre expresión del medio, defendiendo y validando el acceso a la información de la audiencia para construir una comunicación más democrática en la que exista un auténtico pluralismo que combata la concentración y facilite que los ciudadanos accedan en forma más directa al espacio público desde donde contribuyan a la construcción del capital social que sustenta la participación activa que da lugar a la formación de ciudadanía.

La tercera gran conclusión resultante de esta investigación estriba en la dificultad de explicar qué es la ciudadanía. Existen multiplicidad de significados: los legales, los políticos, los sociales. En todos ellos hay distinciones que evidencian que no todos somos ciudadanos, pero lo más relevante es que no siempre somos ciudadanos. Es ahí en donde yace la tercera conclusión de esta investigación: lo que nos define como ciudadanos no es ni la edad, ni la posesión de una credencial de elector, sino los actos de ciudadanía que llevamos a cabo. El más evidente de los actos de ciudadanía que solemos realizar es la participación en cualquiera de sus manifestaciones. Estos actos suelen ser ocasionales y están motivados por causas externas. De lo que se trata la ciudadanía es de hacer consistentes esos actos, para que sean menos esporádicos y menos proclives a ser motivados por factores externos, haciéndolos más frecuentes y mayormente propiciados por la voluntad individual de involucrarse en los asuntos colectivos. Un deseo de ejercer una ciudadanía endógena.

En ese sentido, la formación que los medios social-comunitarios proporcionan es invaluable.

\section{REFERENCIAS}

Barbero, J. M. (2011). Comunicación, espacio público y ciudadanía. Revista Folios, núm. 23b. Recuperado de http://aprendeenlinea.udea.edu.co/revistas/index.php/folios/article/view/ $11800 / 10726$

Bruzzone, D. (2015). Introducción. Voces abiertas Comunicación, politica y ciudadanía en América Latina. Argentina: ClACSO.

Gumucio-Dagon, A. (2011). Comunicación para el cambio social: clave del desarrollo participativo. Recuperado de http://www.redalyc.org/pdf/860/86020038002.pdf

Gutiérrez Vidrio, S. (2011). Representaciones sociales y construcción de la ciudadanía en jóvenes universitarios. Recuperado de http://www.redalyc.org/articulo.oa?id=99815920002 
INE y COLMEX.(2015)Informe Paíssobre la calidad de la ciudadanía en México. Recuperado de http:// www.ine.mx/archivos2/s/DECEYEC/EducacionCivica/Documento_Principal_23Nov.pdf

Mari Sáez, V. M. (2010). El enfoque de la comunicación participativa para el desarrollo y su puesta en práctica en los medios comunitarios. Recuperado de http://www.razonypalabra.org.mx/N/N71/ VARIA/27\%20MARI_REVISADO.pdf https://doi.org/10.2307/j.ctvn96f5x.8

Navarro Díaz, L. R. (2010). Una reflexión sobre los medios ciudadanos: esferas públicas, movilizadores de identidades y contraidentidades de los sujetos políticos en Colombia. Recuperado de https://www. researchgate.net/publication/277264428_Una_reflexion_sobre_los_medios_ciudadanos_ esferas_publicas_movilizadores_de_identidades_y_contraidentidades_de_los_sujetos_politicos_en_Colombia https://doi.org/10.35537/10915/66125

Olvera, A. J. (2014). Ciudadanía y participación ciudadana en México. Hacia una nación de ciudadanos. México: Conaculta-FCE.

Ramos, V.M. (2007). La radio comunitaria frente a los grupos de poder. Recuperado de https://dialnet. unirioja.es/servlet/articulo?codigo $=2597270$

Rizo, M. (2009). Participación en Memorias del Tercer Seminario de Comunicación Indígena. Radio Teocelo. Ojo de Agua Comunicación. 13-15. Oaxaca, México. Recuperado de http://ojodeaguacomunicacion.org/joomla2014/images/archivos_pdfs/memoria_seminario_3.pdf

Rodríguez, C. (2009). De medios alternativos a medios ciudadanos: trayectoria teórica de un término. Recuperado de http://www.scielo.org.co/scielo.php?script=sci_nlinks\&ref=000135\&pi$\mathrm{d}=$ S0120-4807201600010001100021\&lng=es https://doi.org/10.26620/uniminuto.mediaciones.10.12.2014.76-87

Rodríguez, C. y Quijano, M. (2014). Por una comunicación pensada desde las necesidades de las comunidades. Recuperado de http://biblioteca.uniminuto.edu/ojs/index.php/med/article/view/541

Unesco. (2015). Educación para la ciudadanía mundial. Recuperado de http://unesdoc.unesco.org/ images/0023/002338/233876s.pdf 